\section{Cureus}

Received 12/04/2014

Review began 12/06/2014

Review ended 12/23/2014

Published 12/28/2014

C) Copyright 2014

Breshears et al. This is an open access article distributed under the terms of the Creative Commons Attribution License CC-BY 3.0., which permits unrestricted use, distribution, and reproduction in any medium, provided the original author and source are credited.

\title{
Temporalis Muscle Suspension on Synthetic Cranioplasty: Technical Note
}

\author{
Jonathan D. Breshears ${ }^{1}$, Joseph A. Osorio ${ }^{1}$, William Hoffman ${ }^{2}$, Michael W. McDermott ${ }^{1}$ \\ 1. Department of Neurological Surgery, University of California, San Francisco 2. Department of Plastic \\ Surgery, University of California, San Francisco
}

$\square$ Corresponding author: Jonathan D. Breshears, breshearsj@neurosurg.ucsf.edu Disclosures can be found in Additional Information at the end of the article

\section{Abstract}

Temporal hollowing is a disfiguring complication after a craniectomy operation resulting from temporalis muscle atrophy, contraction, and adhesion to the underlying dura. We describe a technique for temporalis muscle re-suspension utilizing multi-hole cranial plates and screws to recreate the superior temporal line on an otherwise smooth synthetic cranioplasty implant.

Categories: Neurosurgery

Keywords: cranioplasty, temporal wasting, craniectomey, temporal hollowing, temporalis muscle

\section{Introduction}

Temporal hollowing can be a disfiguring complication after a craniotomy or craniectomy operation, and is associated with poor temporalis muscle function and temporomandibular joint pain [1-3]. This cosmetic and functional disfigurement involving the temporalis muscle is exacerbated after hemi-craniectomy, commonly utilized in patients with traumatic brain injury or large ischemic stroke. The large skull defect frequently leads to temporalis muscle atrophy, contraction, and adhesion to the underlying dura over the weeks to months before cranioplasty. Separating the muscle from the dura at the time of cranioplasty is difficult and creates more muscle ischemia and scarring. Often, the native bone flap is either lost or discarded due to an infection; this subsequently requires the use of a synthetic cranioplasty implant to repair the skull defect. Temporalis re-suspension is uniquely challenging with a synthetic implant versus native bone, where a cuff of tissue along the superior temporal line is often left behind to suture the muscle to at the time of cranioplasty. Custom implants can produce an excellent cosmetic result with restoring the bony defect to the original contour of the skull; however, temporal hollowing can undermine these results if adequate attention is not given to resuspension of the temporalis muscle. In order to achieve this, the temporalis muscle must be dissected off the dura and re-suspended on the synthetic cranioplasty implant.

Numerous techniques have been described for suspension of the temporalis muscle after craniotomy or craniofacial reconstruction, including suturing to microscrews, plates, holes drilled in the bone, or a myofacial cuff, all associated with satisfactory results [4-10]. In this technical note, we describe an adaptation of these techniques for suspension of the temporalis muscle using multi-hole plates to re-create the superior temporal line on a smooth synthetic cranioplasty implant that optimizes cosmesis, and improves the function of the temporalis muscle.

\section{Technical Report}




\section{Cureus}

The UCSF Committee on Human Research does not require approval for case studies including up to three individuals. Informed patient consent was obtained.

A 27-year-old man, with a history of a previous right-sided hemi-craniectomy for an epidural hematoma after falling from a height of two stories (Figure 1), was taken to the operating room three months after his initial injury for implantation of a custom synthetic cranioplasty implant. After elevation of the scalp, the temporalis muscle was dissected off the underlying dura. The cranioplasty was inserted and fixed to the skull with titanium plates. These plates were recessed, to prevent erosion through the skin, by drilling a small groove in both the implant and the skull. The superior temporal line was recreated by fixing two long plates on the synthetic implant with screws. The temporalis muscle was then attached to these plates with 2.0 vicryl sutures spaced approximately $1 \mathrm{~cm}$ apart (Figure 2). At two months follow-up, the patient was pleased with the cosmetic results. He was noted to have minimal temporal hollowing and symmetric jaw movements (Figure 3).

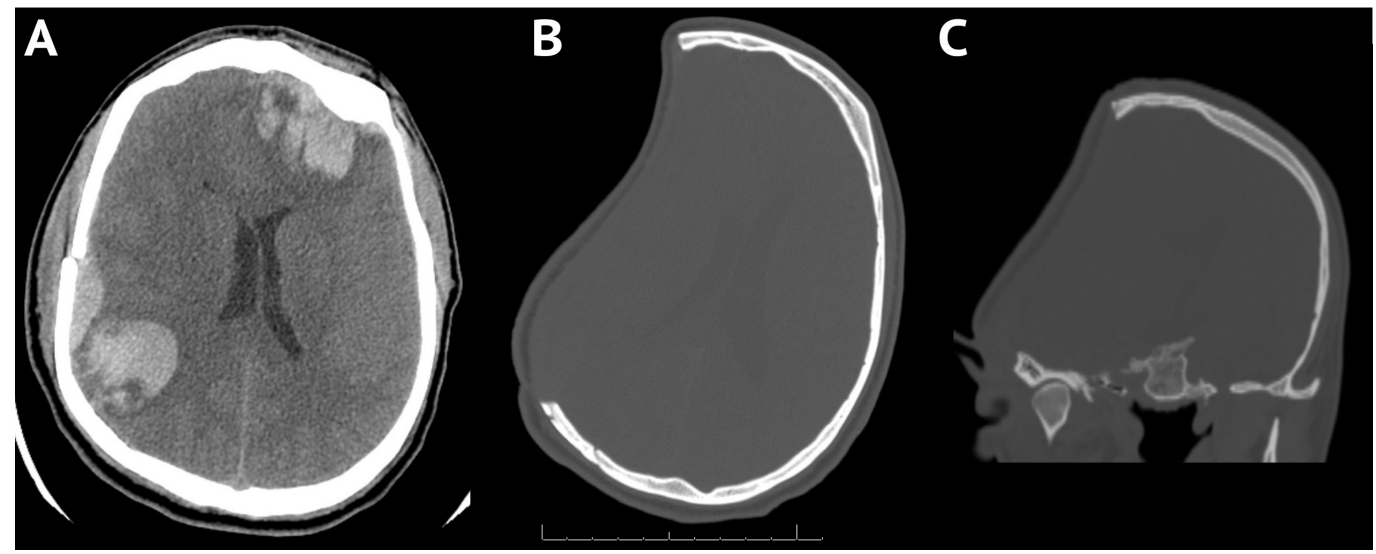

\section{FIGURE 1: Pre- and postoperative imaging}

A) Axial non-contrast head CT showing right parietal and left frontal intraparenchymal hemorrhage, a right-sided epidural hematoma, and overlying skull fracture. B \&C) Axial and coronal head CT (bone windows) showing the large calvarial defect after hemicraniectomy. This imaging was obtained just prior to cranioplasty, when the cerebral edema, hemorrhages, and contusions had resolved. 


\section{Cureus}

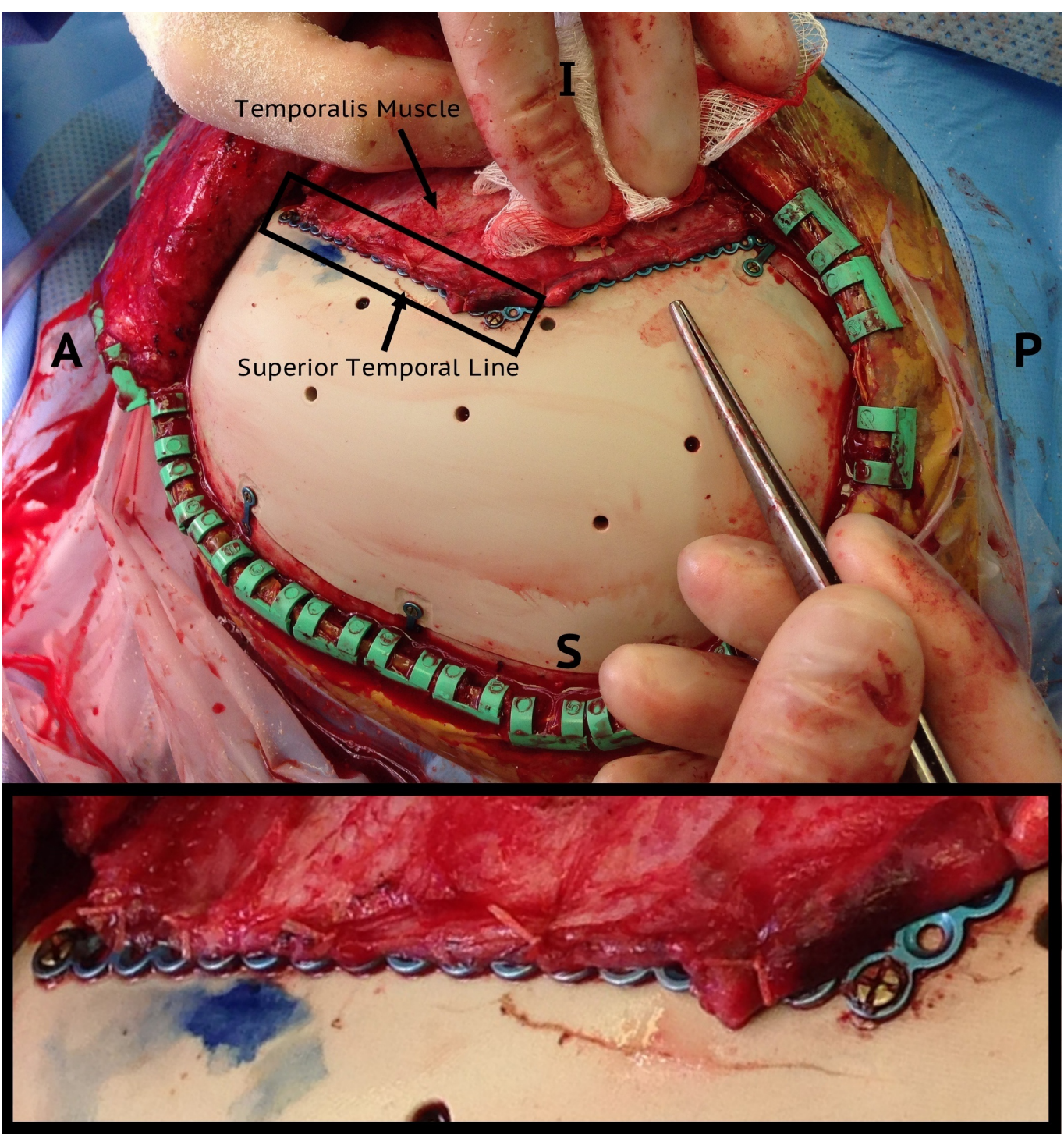

FIGURE 2: Intraoperative photograph showing the synthetic cranioplasty implant fixed in place with recessed titanium plates.

The temporalis muscle was dissected off the dura and suspended from two long titanium plates fashioned to recreate the superior temporal line (inset). $\mathrm{A}=$ anterior, $\mathrm{P}=$ posterior, $\mathrm{S}=$ superior, I = inferior 


\section{Cureus}

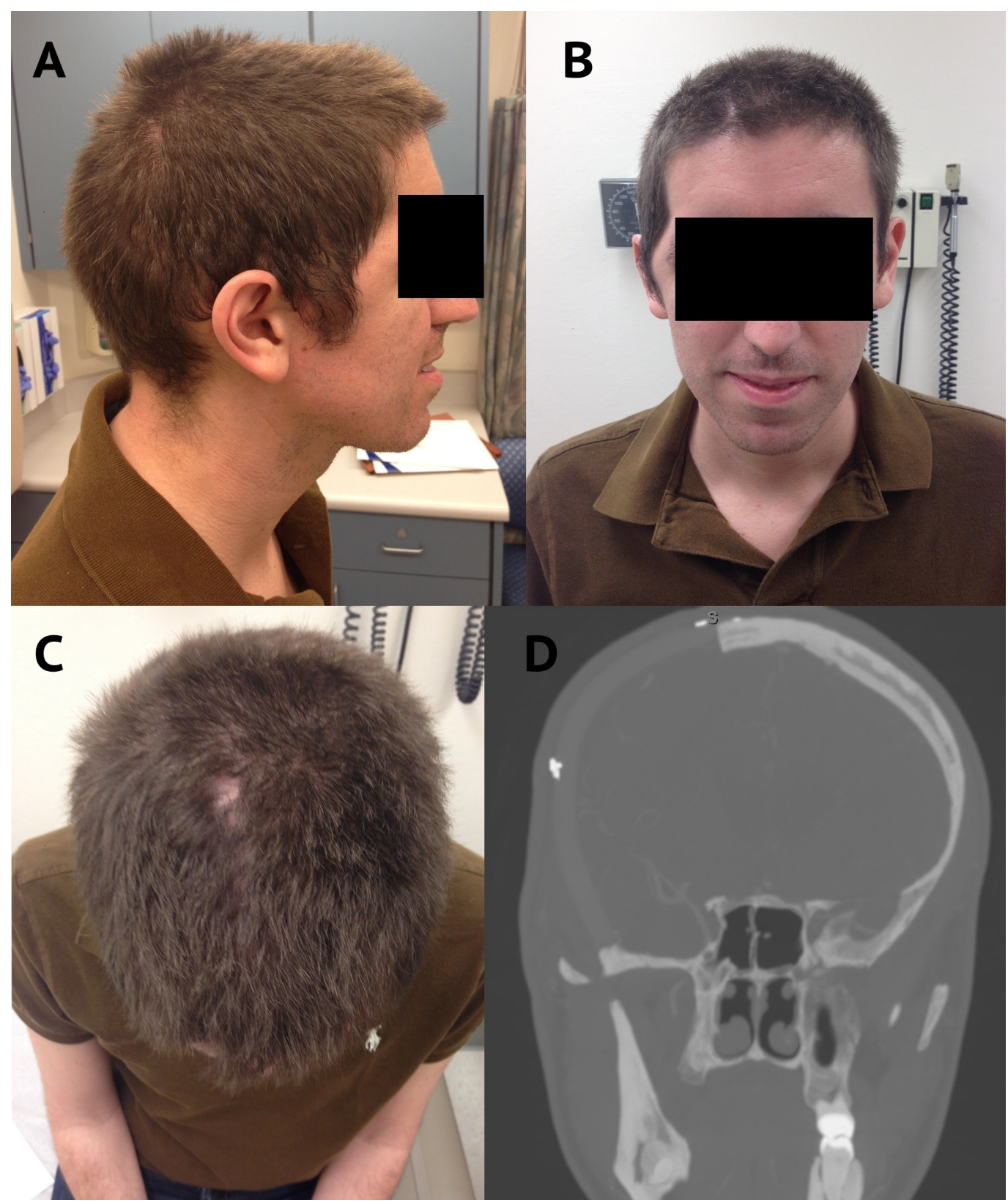

FIGURE 3: Postoperative photographs (with permission) and CT imaging, six weeks out from cranioplasty showing an overall good cosmetic result.

A small degree of temporal hollowing can be appreciated in (B). D) Coronal head CT angiogram (bone windows) showing atrophic right temporalis muscle attached to the plate on the synthetic implant, resulting in only minor asymmetry.

\section{Discussion}

Temporal hollowing is a disfiguring complication after a craniectomy operation resulting from temporalis muscle atrophy, contraction, and adhesion to the underlying dura. We describe a technique for temporalis muscle re-suspension utilizing multi-hole cranial plates and screws to recreate the superior temporal line on an otherwise smooth synthetic cranioplasty implant. In conjunction with a custom-made implant, this technique can optimize cosmetic and functional 
outcomes in patients who are at high risk for disappointing and disfiguring cosmetic results. Further, proper re-implantation of the muscle may also lead to improved function for chewing and symmetry of jaw opening and closure.

\section{Conclusions}

Special attention must be paid to re-suspension of the temporalis muscle at the time of cranioplasty to avoid disfiguring cosmetic results and poor function. Re-creation of the superior temporal line on a smooth synthetic custom implant, as described in this report, has produced favorable results in the senior author's 10 year experience (approximtely 40 cases) with this technique.

\section{Additional Information Disclosures}

Human subjects: Consent was obtained by all participants in this study. UCSF Committee on Human Research issued approval N/A. The UCSF Committee on Human Research does not require approval for case studies including up to three individuals. Animal subjects: All authors have confirmed that this study did not involve animal subjects or tissue. Conflicts of interest: In compliance with the ICMJE uniform disclosure form, all authors declare the following: Payment/services info: All authors have declared that no financial support was received from any organization for the submitted work. Financial relationships: All authors have declared that they have no financial relationships at present or within the previous three years with any organizations that might have an interest in the submitted work. Other relationships: All authors have declared that there are no other relationships or activities that could appear to have influenced the submitted work.

\section{References}

1. Kadri PA, Al-Mefty O: The anatomical basis for surgical preservation of temporal muscle . J Neurosurg. 2004, 100:517-22.

2. Abdulazim A, Filis A, Sadr-Eshkevari P, Schulte F, Sandu N, Schaller B: Postcraniotomy function of the temporal muscle in skull base surgery: Technical note based on a preliminary study. ScientificWorldJournal. 2012, 2012:427081. 10.1100/2012/427081

3. de Andrade Júnior FC, de Andrade FC, de Araujo Filho CM, Carcagnolo Filho J: Dysfunction of the temporalis muscle after pterional craniotomy for intracranial aneurysms. Comparative, prospective and randomized study of one flap versus two flaps dieresis. Arq Neuropsiquiatr. 1998, 56:200-5.

4. Spetzler RF, Lee KS: Reconstruction of the temporalis muscle for the pterional craniotomy. Technical note. J Neurosurg. 1990, 73:636-7.

5. Zager EL, DelVecchio DA, Bartlett SP: Temporal muscle microfixation in pterional craniotomies. Technical note. J Neurosurg. 1993, 79:946-7.

6. Hönig JF: V-tunnel drill system in craniofacial surgery: A new technique for anchoring the detached temporalis muscle. J Craniofac Surg. 1996, 7:168-9.

7. Eppley BL, Sadove AM: Microscrew anchorage techniques in craniofacial surgery. J Craniofac Surg. 1991, 2:71-3.

8. Day JD, Levy M, Fukushima T: Temporal muscle fixation. J Neurosurg. 1995, 82:701; author reply 701-2.

9. Barone CM, Jimenez DF, Boschert MT: Temporalis muscle resuspension using titanium miniplates and screws: Technical note. Neurosurg. 2001, 48:450-1.

10. Webster K, Dover MS, Bentley RP: Anchoring the detached temporalis muscle in craniofacial surgery. J Craniomaxillofac Surg. 1999, 27:211-3. 